\title{
Nuclear Power and Japan's Collective Future: Understanding Beliefs About How Nuclear Policies Will Affect Society
}

\author{
Joonha Park, ${ }^{1}$ Paul Bain, ${ }^{2}$ and Takashi Kusumi ${ }^{3}$ \\ ${ }^{1}$ Faculty of Communications, Nagoya University of Commerce and Business, Nisshin, Japan \\ ${ }^{2}$ School of Psychology and Counselling, Queensland University of Technology, Brisbane, Australia \\ ${ }^{3}$ Graduate School of Education, Kyoto University, Japan
}

\begin{abstract}
$\mathrm{D}$ espite ongoing controversies regarding possible directions for the nuclear plants program throughout Japan since the Fukushima disaster, little has been researched about people's belief structure about future society and what may affect their attitudes toward different policy options. Beyond policy debates, the present study focused on how people see a future society according to the assumptions of different policy options. A total of 125 students at Japanese universities were asked to compare a future society with society today in which one of alternative policies was adopted (i.e., shutdown or expansion of nuclear reactors) in terms of characteristics of individuals and society in general. While perceived dangerousness of nuclear power predicted attitudes and behavioural intentions to make personal sacrifices for nuclear power policies, beliefs about the social consequences of the policies, especially on economic development and dysfunction, appeared to play stronger roles in predicting those measures. The importance of sociological dimensions in understanding how people perceive the future of society regarding alternative nuclear power policies, and the subtle discrepancies between attitudes and behavioural intentions, are discussed.
\end{abstract}

Keywords: nuclear plants, Japan, collective future, beliefs about future society

Japan's 2011 Fukushima Daiichi nuclear disaster has once again aroused attention and debate about the future of nuclear energy. In particular, people and their governments are confronted by the decision of whether to shut down nuclear reactors or continue to expand their use (Butler, Parkhill, \& Pidgeon, 2011; Pidgeon, Lorenzoni, \& Poortinga, 2008; Poortinga \& Pidgeon, 2003). These diverging policy directions may have substantially different effects on Japanese society ('Three years after', 2014). Accordingly, Japanese views can give insights into two starkly different futures for nuclear energy: to continue the expansion of nuclear power, resulting in more nuclear reactors over time; or to shut down nuclear reactors and build alternative sources of energy supply. In either case, these policies will have wider effects beyond just where energy comes from; they can affect scientific and economic development, people's health and wellbeing, and even how people see themselves as a society.

At the forefront of the controversial political and public debate about nuclear power is its inherent danger, due to the devastating consequences if something goes wrong (Whitfield, Rosa, Dan, \& Dietz, 2009). However, whichever future Japan pursues has implications beyond judgments about the risks of nuclear power, as both shutting down and expanding nuclear energy will have substantial economic and social consequences, and result in significant social change. This broader consideration of nuclear power and its social benefits, and consequences for future generations, is particularly salient after a nuclear disaster (Prati \& Zani, 2012). The aim of the present research was to examine these social benefits for future generations in much more detail than previous research, to understand the types of social changes people believe that shutting down, or expanding, nuclear energy will have on society; and to identify which of these beliefs are most critical to their support for either shutting down or expanding nuclear energy production.

Beliefs about the future are at the heart of any judgment about the consequences of proposed government

Address for correspondence: Dr Joonha Park, Faculty of Communications, Nagoya University of Commerce and Business, Nagoya, Japan. Email jpark@nucba.ac.jp 
and social policies. In particular, people's projections about their society's future plays an important role (Bain, Hornsey, Bongiorno, Kashima, \& Crimston, 2013; Bickerstaff, Lorenzoni, Pidgeon, Poortinga, \& Simmons, 2008), a point emphasised by the prominent social activist Noam Chomsky (1999/1970): 'Social action must be animated by a vision of a future society, and by explicit judgements of value concerning the character of this future society' (p. 100). Expressed another way, people generate a sense of what society will be like under a proposed social change to help them decide whether to support or oppose it.

It is only recently that theoretical developments in social psychology have allowed people's projections about their society in the future to be examined in systematic ways. Bain et al. (2013) developed and validated the 'collective futures' framework, identifying two levels and four basic dimensions underpinning people's beliefs about the future of society. The two levels of social consequences are 'Sociological' and 'character'. The sociological level relates to the broad living conditions of a society, and typically reduces to two dimensions: development (e.g., economic, scientific, and community development and progress), and dysfunction (e.g., crime, violence, corruption, and disease). The Character level reflects beliefs about the typical traits of people in society, including the two fundamental dimensions of ingroup stereotypes (Fiske, Cuddy, \& Glick, 2006; Judd, JamesHawkins, Yzerbyt, \& Kashima, 2005; Leach, Ellemers, \& Barreto, 2007), here called Benevolence (levels of warmth and morality) and Competence (levels of capability and organisation).

Using these dimensions, people have considered how proposed social policies have consequences for society in the future. These projections about the consequences of social policies have been linked with policy support and action across a diverse range of policies, including legalising marijuana, addressing climate change, religious tolerance, relaxing abortion, and Korean political unification (Bain, Hornsey, Bongiorno, \& Jeffries, 2012; Bain et al., 2013; Milfont, Bain, Souza, Gouveia, \& Kashima, 2014; Park \& Bain, 2013).

Hence, in the present research we used the collective futures framework to investigate whether people's beliefs about the broader sociological consequences of expanding or shutting down the nuclear program are related to their support for these policies. We aimed to identify: (1) the types of social consequences people foresee from shutting down or expanding nuclear power; and (2) whether these social consequences were related to people's support for, and opposition to, nuclear power.

Previous research on attitudes towards nuclear policies suggests that Development may be the most salient dimension, particularly with regard to economic benefits. Although the actual economic costs and benefits of nuclear power options are debated, people with a pro-nuclear attitude tend to be more optimistic about the economic benefits of nuclear power and less pessimistic about its environmental and psychological risks (van der Pligt, Eiser, \& Spears, 1984). The present research included examining people's beliefs about economic consequences, but went much further in investigating the widest range of social consequences to date.

In investigating how beliefs about social consequences are related to support for nuclear shutdown or expansion, it is important to show that these effects are independent of the aspect of nuclear power that typically dominates public debate - its dangerousness. Beliefs about the potential danger of nuclear power are an important predictor of people's attitudes to nuclear power evaluation (e.g., Drottz-Sjöberg \& Sjoberg, 1990; Hughey \& Sundstrom, 1988; Visschers \& Siegrist, 2013). A study that compared perceptions of nuclear power before and after the Chernobyl accident suggested that knowledge about the dangers of nuclear power was associated with more negative evaluations (McDaniels, 1988). Thus, we included items to measure the perceived danger of nuclear power, to determine whether the effects of projected social consequences are not reducible to the general impression that nuclear power is dangerous.

We aimed to examine the way perceived future society and danger of nuclear power predict two factors affecting actual behaviour: people's attitudes (support or opposition to nuclear policies) and personal sacrifice (willingness to bear potential costs of their preferred policy). The concept of sacrifice has been little examined in both activist and academic conversations about environmental politics, including nuclear policy (Maniates \& Meyer, 2010), and compared with attitudes, it is not related specifically to nuclear power but more to general awareness about energy saving (Prati \& Zani, 2012). In short, we attempted to understand why people endorsed their preferred nuclear policy, and whether they were prepared to bear the consequences of this policy.

We hypothesised that perceived danger of nuclear power would be associated with people's attitudes and personal sacrifice, replicating the previous findings (e.g., Drottz-Sjöberg \& Sjoberg, 1990; Hughey \& Sundstrom, 1988; Visschers \& Siegrist, 2013). More importantly, we expected that different beliefs about future society would affect people's attitudes and willingness to make personal sacrifice. To our knowledge, no studies have examined broad sociological consequences on nuclear policy issues, and we do not make strong predictions about which projections about society will be most influential for attitudes and personal sacrifice. However, Bain et al. (2013) found that Development (economic, scientific, and community progress) and Benevolence (the level of caring and morality in the community) dimensions were most strongly and consistently related to attitudes and actions across a broad range of issues, so our expectation was that these dimensions would also show the strongest relationships with attitudes and personal sacrifice for nuclear policies. 


\section{Table 1}

Summary of Factor Analysis Results (Pattern Matrix) for Sociological Dimensions

\begin{tabular}{lllll}
\hline & Factor 1 & Factor 2 & Factor 3 & Factor 4 \\
\hline Financial wealth & .95 & & & \\
Economic development & .79 & & & \\
Volunteering & & .69 & & \\
Scientific progress & & & .90 & \\
Technological progress & & .83 & \\
Corruption & & & .80 \\
Poverty & & & .52 \\
National security & & & .49 \\
Disease & & .43 \\
Violent crime & .31 & .34 & .34 \\
Sense of community & & .31 & .34 \\
Healthcare standards & .52 & & .33 \\
\hline
\end{tabular}

Note: The high factor loading groups are highlighted in bold.

\section{Method}

\section{Participants}

Data was collected from 125 university students in Tsukuba and Kyoto, Japan, from 6 to 13 months after the Fukushima accident. Their mean age was 21.4 years old $(S D=4.45)$, and $60.8 \%$ were male. They participated in the study as part of a course requirement.

\section{Materials and Procedure}

Participants completed pencil and paper surveys with the following materials.

Nuclear policy scenarios. Participants were randomly assigned to one of two versions of a policy scenario. In the 'shutdown' scenario, they were instructed to think about Japanese society in 2040 if all nuclear reactors were shut down. In the 'expansion' scenario, they were instructed to think about Japanese society in 2040 if there were more active nuclear reactors compared to today. To reinforce the scenario, all participants were asked to take a few moments to think about what Japan would be like in that scenario, in comparison to Japan today. They then made the ratings below.

Collective futures. Collective future ratings were used as the main independent variables. Items representing Sociological and Character dimensions of society were adapted from Bain et al. (2013). Eighteen items assessing Character were the same as in Bain et al. (2013; see their Table 1), including considerate and immoral (reversed) to represent Benevolence, and capable and lazy (reversed) to represent Competence. These items were rated with reference to the scenario they considered for Japanese society in 2040, using an 11-point scale labelled from -5 (much less typical than in Japanese society today), through 0 (no different from Japanese society today), to 5 (much more typical than in Japanese society today). These items formed reliable scales for Benevolence $(\alpha=.74)$ and Competence $(\alpha=.79)$.

Sociological dimensions. For sociological dimensions, we selected items from Bain et al. (2013) deemed most rel- evant to nuclear power, and included additional items expected to be especially salient when considering nuclear futures (e.g., national security, healthcare). These were rated on an 11-point scale that was slightly different from previous studies. Whereas the original collective futures dimensions focused on prevalence (e.g., whether disease would be more or less widespread), more recent approaches have used evaluations (e.g., whether the issue of disease would improve or worsen; e.g., Bain et al., 2015). We used the second 11-point evaluative scale, labelled from -5 (much worse compared to Japanese society today), through 0 (no different from Japanese society today), to 5 (much improved compared to Japanese society today). As the items differed from previous research, we describe the structure of these items in the Results section.

Danger of nuclear power. Beliefs about the danger of nuclear power were measured using two items. Participants were asked to rate the extent to which they agreed or disagreed that generating electricity from nuclear power ' ... is a hazard to human health', and '.. creates dangerous waste'. These items formed a reliable scale $(\alpha=.78$; $r=.64)$.

Support for shutting down/expanding nuclear power. As opposing the shutting down of nuclear reactors does not necessarily mean supporting expansion, we used separate items to assess support for shutting down/expansion. Participants were asked 'How strongly do you support or oppose the shutdown of nuclear reactors in Japan?' and 'How strongly do you support or oppose expansion of nuclear reactors in Japan?', both using 7-point scales labelled -3 (strongly oppose), -2, (oppose), -1 (slightly oppose), 0 (neither oppose nor support), 1 (slightly support), 2 (support), and 3 (strongly support).

Personal sacrifice for shut down/expansion of nuclear power. Participants also indicated their personal sacrifice for shutting down or expanding nuclear power on a 7-point scales labelled -3 (very unlikely), -2 (unlikely), -1 (slightly unlikely), 0 (undecided), 1 (slightly likely), 2 (likely), and 3 (very likely). Again, these were split into separate scales. Personal sacrifice for shutdown was measured using four items relating to their willingness to do the following to support shutting down all nuclear reactors in Japan: paying higher prices for energy, accepting cuts in standard of living, conserving energy in their household, and paying higher taxes $(\alpha=.91)$. Personal sacrifice for expanding the nuclear program used the same items, with the omission of 'conserving energy in the household' (as the equivalent of 'using more energy in the household' for the purpose of promoting nuclear reactors was deemed unrealistic), which also resulted in a highly reliable scale $(\alpha=.94)$. See the Appendix for a summary of the psychometric properties (mean, skewness, and kurtosis) of the major study variables and their intercorrelations. 


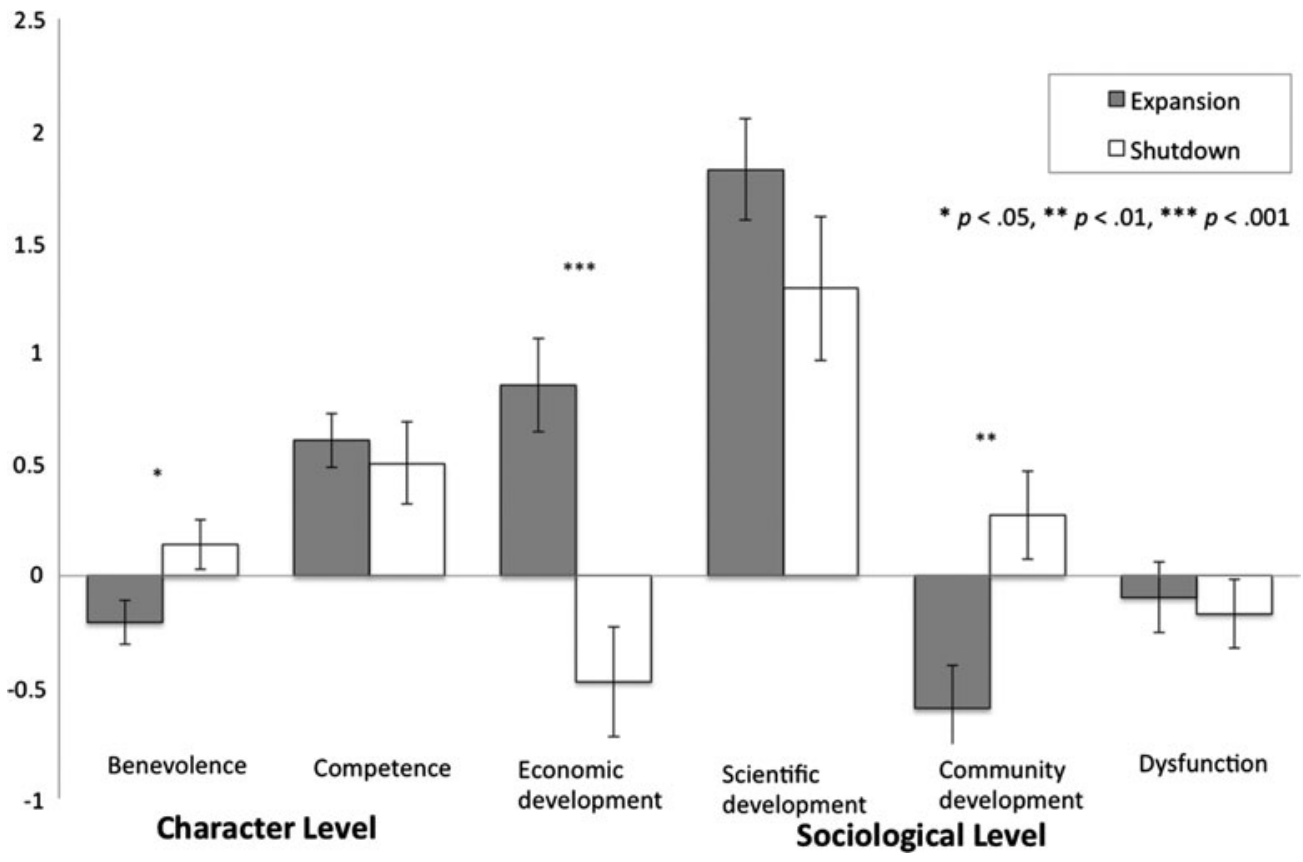

Figure 1

Means and standard errors for collective futures dimensions in nuclear power expansion and shutdown scenarios.

\section{Results}

Four participants were excluded from the analysis due to strong evidence of pattern-responding across multiple scales.

\section{Sociological Dimensions of Collective Futures}

As the items for the Sociological level differed from previous research, we performed a factor analysis to understand the structure of responses and whether they differed from the typical distinction between Development and Dysfunction. A factor analysis with oblique rotation suggested four factors that explained $66 \%$ of the variance, which was also supported by parallel analysis. As can be seen in Table 1, these four factors reflected finer distinctions being made between economic development, scientific development, and community development for the issue of nuclear power. On the first factor, economic items loaded strongly (rotated loadings above .81 for economic development and financial wealth). The second factor included science items (rotated loadings above .87 for scientific progress and technological programs). The third factor included only one development item, volunteering (rotated loading $=.66$ ). Finally, the fourth factor included dysfunction items (rotated loadings above .43 for national security, poverty, corruption, and disease). Healthcare standards, community, and violent crime items crossloaded on multiple factors. Items listed above that loaded exclusively on each factor were used to form a reliable two-item scale for Economic Development ( $\alpha=.88$ ), a two-item scale for Scientific Development $(\alpha=.92)$, a one-item measure for Community Development ('volun- teering'), and a four-item scale for Dysfunction $(\alpha=.63)$. Covariance between factor scores varied from -.98 to 2.32.

\section{Beliefs About the Social Consequences of Shutting Down or Expanding Nuclear Power}

Using the Character dimensions and the new Sociological dimensions of beliefs about society's future, we next turned to understanding how participants thought society would change in the shutdown and expansion nuclear policy scenarios. We made separate comparisons across scenarios for each dimension, with the means and standard errors shown in Figure 1.

Comparisons across scenarios showed that, compared to a shutdown policy, an expansion policy was believed to result in significantly higher levels of Economic Development, $t(119)=4.11, p<.001$, but significantly lower levels of Community Development, $t(119)=-3.12, p=$ .002 , and Benevolence, $t(119)=-2.35, p=.021$. Levels of Competence characteristics increased to a similar degree in both shutdown and expansion scenarios, $t(119)$ $=.47, p=.64$. Overall, these patterns demonstrate that the two potential nuclear policies are believed to produce marked differences in Japanese society, with expansion fostering Economic Development at the expense of a sense of community (Community Development) and Benevolence, and shutdown fostering relatively more Community Development and benevolence, but at the expense of lesser Economic Development. 


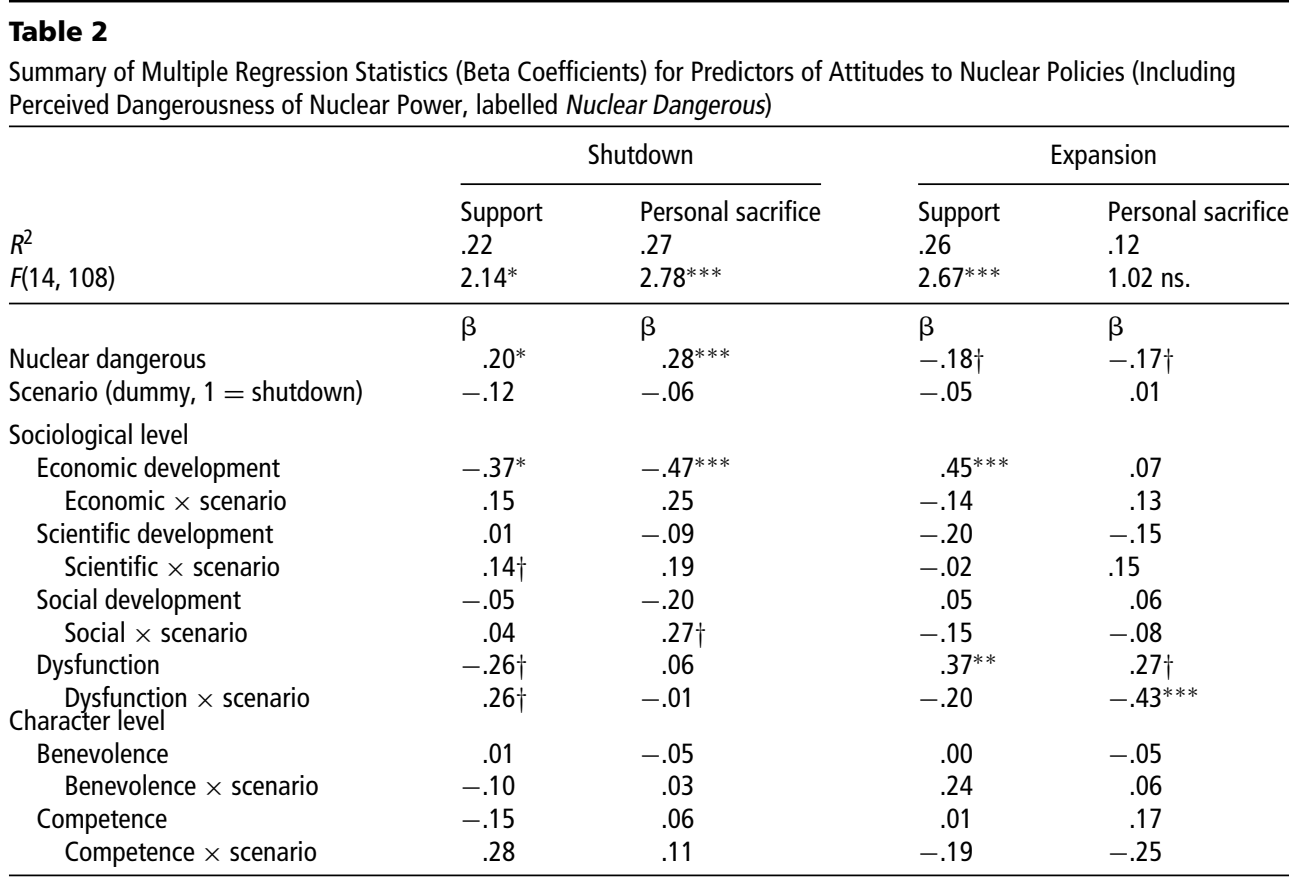

Note: $\dagger p<.10,{ }^{*} p<.05,{ }^{* *} p<.01{ }^{* * *} p<.001$

\section{Predicting Support and Personal Sacrifice for Shutting Down or Expanding Nuclear Power}

While identifying beliefs about the differing social consequences of shutting down or expanding nuclear power is important in itself, here we address whether these beliefs translate into support for shutting down or expanding nuclear power. In particular, we aimed to identify whether these beliefs about sociological consequences could predict support over and above the dominant dimension used to understand public attitudes towards nuclear power - perceptions of its dangerousness. Therefore, we performed a series of regressions where we regressed support/personal sacrifice for either shutting down or expanding nuclear power on the Danger scale and the collective futures dimensions. In each regression we also included a dummy variable for each version (with expansion coded 0 as the reference variable) and interaction terms for each collective future dimension. These regressions are shown in Table 2.

Turning first to the two measures promoting shutting down nuclear power (i.e., support and personal sacrifice for shutdown), the belief that nuclear power is dangerous was related to both scales. However, beliefs about the social consequences of these policies were also related to support, independently of dangerousness. In particular, for those who considered the consequences of expanding nuclear power (the reference condition), beliefs that expansion would result in greater Economic Development were opposed to shutting down nuclear power. There was no interaction effect between scenarios, implying that this relationship was not significantly weaker when considering shutting down nuclear power. The pattern was sim- ilar for the personal sacrifice model, so that participants who believed that expansion would result in greater Economic Development were less likely to consider the personal sacrifice for shutting down nuclear power, regardless of alternative policies. Also, for participants in the expansion condition, beliefs that expansion would result in less Dysfunction meant they were opposed to shutting down nuclear power. The interaction effect showed that these relationships were somewhat weaker in the shutdown condition. This pattern was not found for the personal sacrifice model. Notably, neither support nor personal sacrifice for shutting down nuclear power was related to beliefs about consequences of policies for the Character dimensions.

A somewhat different story emerges for support and personal sacrifice for expanding nuclear power. While noting that the overall model for personal sacrifice for expansion was not significant due to the inclusion of many variables that predicted this poorly, believing that nuclear power is dangerous was the only marginal predictor in both models. Remarkably, beliefs about the consequences of the policies on Economic Development played a strong role in predicting support for expansion, which did not vary significantly across scenarios. There was no such effect for the personal sacrifice model. However, both models were associated with beliefs about the consequences of these policies on the Dysfunction dimension. When participants considered a future society where nuclear power has expanded, they supported this expansion to the extent they believe it would also reduce Dysfunction in society (e.g., greater national security, less poverty, corruption, and disease). These relationships were significantly weaker when participants considered a shutdown scenario, where 
there were null relationships. Again, Character dimensions were unrelated to people's support or personal sacrifice for expansion.

\section{Discussion}

Both shutting down and expanding the nuclear program in Japan were expected to have wide-ranging consequences for Japanese society. Shutting down nuclear reactors was expected to increase the level of Benevolence (caring and morality) and Competence characteristics in Japan, and improve Scientific Development and Community Development. However, a shutdown was expected to come at a cost of worse Economic Development and a slight increase in societal Dysfunction, such as corruption and worsened national security. Expanding nuclear power was also expected to lead to increased Competence and Scientific Development, but, unlike the shutdown scenario, it was associated with lower Benevolence and Community Development, but higher Economic Development and no change in Dysfunction.

These perceptions of society's future were related to people's support for shutting down or expanding nuclear power, independently of the perceived dangers of nuclear energy. The strongest finding was for Economic Development. Participants showed the least support and willingness to shut down nuclear power when they thought that expanding nuclear power would promote Economic Development. Relationships between Economic Development and support for shutdown were smaller, but not significantly so, when people considered the shutdown scenario. The positive consequences for Economic Development was also related to support for expanding nuclear power, although not to willingness to sacrifice to expand nuclear power. The belief that expanding nuclear power would reduce Dysfunction in society was also related to support and personal sacrifice for expansion, but the relationship between societal Dysfunction and personal sacrifice for expansion was much lower when people considered shutting down nuclear power. The belief that Dysfunction would be reduced if nuclear power were expanded was also marginally related to lower support for shutting down nuclear energy, but the relationship between Dysfunction and support for shutdown was null when people considered the shutdown scenario.

One message that cuts across these findings is that beliefs about society's future were more strongly related to nuclear policy attitudes when people considered the nuclear expansion scenario rather than the nuclear shutdown scenario. The vision of a more nuclear-dependent future society appears to promote more compelling images of society's future that may influence not just how strongly people react to the idea of shutting down nuclear reactors, but also how strongly they react to building more reactors. While the clear negative of nuclear power - its dangerousness - was related to support for shutdown, and somewhat to opposition to expansion, people gener- ally saw expanding nuclear power as positive for economic development, and the extent to which they did see these positives were linked to more positive attitudes towards nuclear power. The size of the beta weights in the regressions when considering expansion were even stronger for Economic Development than for danger, indicating that this societal consequence in the context of nuclear expansion is critical in understanding when people will support or oppose nuclear policies.

The research also contributes to the theoretical developments in how people understand society's future. Research using the collective futures framework (Bain et al., 2013) has found that economic, scientific and social developments are typically highly correlated and form a single factor. However, in the context of nuclear policies, participants made finer-grained distinctions that separated these components of development. This is most likely due to the specific features of this policy and social context of nuclear energy in post-Fukushima Japan. The Fukushima disaster raised public doubts about science and its failings in preventing the accident, high uncertainty about the long-term economic consequences, and a positive surge in voluntary and community support and help for survivors. Thus, while people typically view scientific, economic and social development as co-occurring, in the present case the areas of divergence may have become particularly salient. This provides a basis for further investigation of people's beliefs about the future, and when and why they view development as unitary or as multifaceted.

The finding that nuclear policy preferences were related to Development - here, economic development specifically - is consistent with previous research showing that Development is a judgment about the future that has consequences for people's attitudes today (Bain et al., 2012). However, that research also found the Character level of Benevolence typically shows the strongest and most consistent relationships with present day attitudes and actions, but for this sample, Benevolence was not related to nuclear policy preferences. This is unlikely due to cultural effects, as Japanese people have shown strong relationships with attitudes and actions in the context of climate change (Bain et al., 2015). We surmise that the public salience of the broad sociological effects of nuclear energy in Japan may have led people to attend to these factors and place less attention and consideration on how policies will affect the character of people in society. This can open avenues for investigation into how the public communication of issues may influence people's own thoughts and considerations about society's future.

A limitation of the research was the reliance on university students, and generalisation to the general public or other cultures should be established, as perspectives on nuclear energy and policy can vary with sociodemographic factors (Kovacs, Eng, \& Gordelier, 2010). Moreover, although we examined behavioural intentions involving personal sacrifice, further research is needed to extend this to actual behaviours, as people do not 
always act in accordance with their stated intentions (Ajzen, Brown, \& Carvajal, 2004). However, the findings from this research show that these broader social beliefs matter, and this helps justify future research using larger public samples and direct behavioral observations.

Although the current study did not include direct behavioural observations, using measures of support and personal sacrifice did highlight areas of divergence between in-principle support of a policy and behavioural intentions to accept personal sacrifice arising from this policy. For expanding nuclear energy, Economic Development strongly predicted attitudes but not personal sacrifice, even though Economic Development showed consistent effects for support and personal sacrifice for shutting down nuclear power. Thus, participants were willing to accept the personal consequences of their support for shutting down nuclear power; for expansion, they appeared less prepared to pay the personal consequences of their support. Likewise, Dysfunction appeared to predict attitudes but not personal sacrifice for shutting down nuclear power, despite its consistent effects for support and personal sacrifice for expanding nuclear power. The sometimes diverging findings for the support and intentions measures shows the benefit of considering these aspects of people's reactions to nuclear policies separately.

The findings have implications for informing public debate about nuclear power in Japan and beyond. Progression in these debates can be fostered by moving beyond focusing in the dangers of nuclear energy to its broader effects on society, and specifically its consequences for Economic Development and societal Dysfunction. Designing policies that can address these concerns may allow governments and advocates of different nuclear power alternatives to address the broader social concerns people hold, and thus create policies that address both social and nuclear objectives. As many societies across the world are now contemplating their present or proposed reliance on nuclear energy (e.g., de Groot, Steg, \& Poortinga, 2013; Siegrist \& Visschers, 2013; Visschers \& Siegrist, 2013), this research shows the importance of greater attention to the broader social consequences of government and other policies for understanding when and why people will support or oppose nuclear power.

\section{References}

Ajzen, I., Brown, T.C., \& Carvajal, F. (2004). Explaining the discrepancy between intentions and actions: The case of hypothetical bias in contingent valuation. Personality and Social Psychological Bulletin, 30, 1108-1121.

Bain, P.G., Hornsey, M, Bongiorno, R., \& Jeffries, C. (2012). Promoting pro-environmental action in climate change deniers. Nature Climate Change.

Bain, P.G., Hornsey, M.J., Bongiorno, R., Kashima, Y., \& Crimston, D. (2013). Collective futures: How projections about the future of society are related to actions and attitudes supporting social change. Personality and Social Psychology Bulletin, 39, 523-539.
Bain, P.G., Milfont, T.L., Kashima, Y., Bilewicz, M., Doron, G., Garðarsdóttir, R.B., ... Saviolidis, N.M. (2015). Co-benefits of addressing climate change can motivate action around the world. Nature Climate Change. Advance online publication. doi:10.1038/nclimate2814

Bickerstaff, K., Lorenzoni, I., Pidgeon, N.F., Poortinga, W., \& Simmons, P. (2008). Reframing nuclear power in the UK energy debate: nuclear power, climate change mitigation and radioactive waste. Public Understanding of Science, 17, 145169.

Butler, C., Parkhill, K., \& Pidgeon, N.F. (2011). Nuclear power after Japan: The social dimensions. Environment: Science and Policy for Sustainable Development, 53, 3-14.

Chomsky, N. (1999/1970). Language and freedom. Resonance, 4, 86-104.

de Groot, J.I., Steg, L., \& Poortinga, W. (2013). Values, perceived risks and benefits, and acceptability of nuclear energy. Risk Analysis, 33, 307-317.

Drottz-Sjöberg, B.-M., \& Sjoberg, L. (1990). Risk perception and worries after the Chernobyl accident. Journal of Environmental Psychology, 10, 135-49.

Fiske, S.T., Cuddy, A.J.C., \& Glick, P. (2006). Universal dimensions of social cognition: warmth and competence. Trends in Cognitive Sciences, 11, 77-83.

Hughey, J.B., \& Sundstrom, E. (1988). Perceptions of Three Mile Island and acceptance of a nuclear power plant in a distant community. Journal of Applied Social Psychology, 18, 880890.

Judd, C.M., James-Hawkins, L., Yzerbyt, V., \& Kashima, Y. (2005). Fundamental dimensions of social judgment: Understanding the relations between judgments of competence and warmth. Journal of Personality and Social Psychology, 89, 899-913. doi:10.1037/0022-3514.89.6.899

Kovacs, P., Eng, T., \& Gordelier, S. (2010). Public attitudes to nuclear power. Paris, France: Organization for Economic Cooperation and Development.

Leach, C. W., Ellemers, N., \& Barreto, M. (2007). Group virtue: The importance of morality (vs. competence and sociability) in the positive evaluation of in-groups. Journal of Personality and Social Psychology, 93, 234-249. doi:10.1037/0022-3514.93.2.234.

McDaniels, T.L. (1988). Chernobyl's effects on the perceived risks of nuclear power: A small sample test. Risk Analysis, 8, 457-461.

Maniates, M., \& Meyer, J. (2010). Sacrifice and a new environmental politics. In M. Maniates \& J. Meyer (Eds.), The environmental politics of sacrifice (pp. 313-320). Cambridge, MA: MIT Press.

Milfont, T.L., Bain, P.G., Souza, R.L.V., Gouveia, V.V., \& Kashima, Y. (2014). Examining how projections about the future of society are related to present-day climate change action. Psico, 45, 359-368.

Park, J., \& Bain, P. (2013, August). Perceptions about future Korea upon possible unification. Paper presented at Asian Association of Social Psychology, Yogyakarta, Indonesia.

Pidgeon, N.F., Lorenzoni, I., \& Poortinga, W. (2008). Climate change or nuclear power - No thanks! A quantitative study 
of public perceptions and risk framing in Britain. Global Environmental Change, 18, 69-85.

Poortinga, W., \& Pidgeon, N.F. (2003). Public perceptions of risk, science and governance: Main findings of a British survey on five risk cases (Technical Report). Norwich, UK: Centre for Environmental Risk.

Prati, G., \& Zani, B. (2012). The effect of the Fukushima nuclear accident on risk perception, antinuclear behavioral intention, attitude, trust, environmental beliefs, and values. Environment and Bahavior, 45, 782-798.

Siegrist, M., \& Visschers, V.H.M. (2013). Acceptance of nuclear power: The Fukushima effect. Energy Policy, 59, 112119.
Three years after: Experts debate on whether Japan needs nuclear energy (2014, March 6). Asahi Shinbun. Retrieved from http://ajw.asahi.com/article/0311disaster/analysis_opinion/ AJ201403060060.

van der Pligt, J., Eiser, R., \& Spears, R. (1984). Public attitudes to nuclear energy. Energy Policy, 12, 302-305.

Visschers, V.H.M., \& Siegrist, M. (2013). How a nuclear power plant accident influences acceptance of nuclear power: Results of a longitudinal study before and after the Fukushima disaster. Risk Analysis, 33, 333-347.

Whitfield, S.C., Rosa, E.A., Dan, A., \& Dietz, T. (2009). The future of nuclear power: Value orientations and risk perception. Risk Analysis, 29, 425-437. 